\title{
Research of Dyeing Thermodynamics and Supramolecular Structure of Luteolin on Wool Fabric
}

\author{
Can Chen1,2, Wei Zhao',2, Wen Liu1, Yuan Zhang1, Huimin Tang1, Dequan $\mathrm{Xu}^{2,3}$, \\ Chunling Zheng ${ }^{1,2}$ \\ ${ }^{1}$ College of Food Science and Light Industry, Nanjing Tech University, Nanjing, China \\ ${ }^{2}$ Institute of Textile Auxiliary and Ecological Dyeing Finishing, Nanjing Tech University, Nanjing, China \\ ${ }^{3}$ College of Chemistry and Chemical Engineering, Wuhan Textile University, Wuhan, China \\ Email: zcl323@139.com
}

How to cite this paper: Chen, C., Zhao, W., Liu, W., Zhang, Y., Tang, H.M., Xu, D.Q. and Zheng, C.L. (2017) Research of Dyeing Thermodynamics and Supramolecular Structure of Luteolin on Wool Fabric. World Journal of Engineering and Technology, 5, 19-28.

https://doi.org/10.4236/wjet.2017.51B002

Received: March 23, 2017

Accepted: April 9, 2017

Published: April 12, 2017

\begin{abstract}
Natural dyestuff of luteolin was isolated and used to dye wool fabric in this paper. Ethanol extraction and high-speed countercurrent chromatography (HSCCC) were used to extract and purify the luteolin from the peanut shell, and the structure of the isolated luteolin was characterized with FTIR techniques. The interaction between dyestuff and fiber was preliminarily discussed through thermodynamic study and supramolecular structure simulation to explain the intrinsic reasons why the color fastness was low when luteolin was applied to dyeing wool fabric. The extraction condition and purification parameter were as follows: $65 \%$ ethanol, ratio of material to liquid $1: 20,80^{\circ} \mathrm{C}, 3$ h, chloroform-methanol-water (4/3/2, V/V), $800 \mathrm{rmp} / \mathrm{min}, 2.0 \mathrm{Mkpa}, 0.5 \mathrm{~mL} /$ min and $280 \mathrm{~nm}$. The results of dyeing thermodynamics showed that the sorption isotherm of luteolin on wool fabric was consistent with Nernst model and similar to the disperse dyestuff. With molecular simulation, luteolin and glycin composed 8 stable complexes whose Laplacian values all were greater than 0 , which suggested typical hydrogen bonds existing. The complex with three hydrogen bonds was proved the most stable. Both studies on thermodynamics and supramolecular simulation revealed that luteolin on wool fabric mainly depended on the weak hydrogen bonds interaction that determined the low dyefastness.
\end{abstract}

\section{Keywords}

Luteolin, Isolation, Dyeing Thermodynamics, Supramolecular Structure, Wool Fabric 


\section{Introduction}

As one of the most upscale textile fibers in textile industry, wool possesses some inherent excellent properties of soft luster, luxurious hand, fine elasticity, good drape property, strong moisture absorption, preferable heat insulating ability, better anti-wrinkling performance, excellent abrasion resistance and stain-resistance ability, especially comfortable to wear. Wool can be used for various worsted and woolen apparel fabric in good quality and make industrial wool fabric and miscellaneous adornments. Wool fibers consist of protein in which the repeated unit is amino acid. The amino acids are linked together by peptide bond (-CO-NH-) to form protein structure. The most important component in wool is keratin that is amphoteric and a complex protein comprised of diversified $\alpha$-amino acid residue [1]. And in general, wool is dyed with acid dyes.

Luteolin is a kind of important flavone, which is present in natural medicine such as honeysuckle, chrysanthemum and scutellariabaicalensis. It also can be found in vegetables and fruits such as celery, carrot and lemon [2] [3]. Luteolin has a C6-C3-C6 structure that contains two benzene rings and one oxygen-containing ring with a $\mathrm{C} 2-\mathrm{C} 3$ carbon double bond. Luteolin also possesses hydroxyl groups at carbons 5, 7, 3' and 4' positions (Figure 1). Numerous studies have indicated that the hydroxyl moieties and $\mathrm{C} 2-\mathrm{C} 3$ carbon double bond in luteolin are responsible for its biochemical and biological properties [2] [4] [5]. Luteolin is widely used in medicine research due to its multiple pharmacological effects, such as antibacterial, antiphlogistic, antioxidative, etc., but infrequently in dyeing research. Luteolin can be used to dye wool fiber through hydrogen-bond interaction because its polyhydroxy and mildly acidic.

Textile is our primary goods and the question whether the manufacturing processes and materials for textile meet our health requirements has aroused wide attention. Because of better biodegradability and compatibility with the environment as well as lower toxicity and more sources, natural dyes excite increasing interests in recent study. Luteolin can be isolated from a wide variety of natural sources. Therefore, luteolin would have broad prospects of application to natural dyestuff in textile dyeing.

\section{Experiments}

\subsection{Materials and Instrumentations}

Peanuts were purchased from agro-product market and wool was obtained from<smiles>O=c1cc(-c2ccc(O)c(O)c2)oc2cc(O)cc(O)c12</smiles>

Figure 1. The molecular structure of luteolin. 
textile market. All other chemicals and reagents used were of analytical grade i.e., Sodium hydroxide, acetic acid, ethanol, methyl alcohol, chloroform and petroleum ether were bought from Sinopharm. The apparatuses, microwave generator (KH-100B), data color (400), vacuum pump (SHB-III), FTIR Spectrometer (Spectrum one), high-speed counter current chromatography (HSCCC-TBE300B) and UV/Visible spectrophotometer (U-2001) were used. The software, Guassian09 and Multi wfn were used for calculation.

\subsection{Luteolin Isolation and Purification}

The peanut shells were shelled by hands in our laboratory, washed and dried by drying oven at $80^{\circ} \mathrm{C}$. The dried peanut shells were grinded completely by pulverizer and immersed in petroleum ether to degrease with the ratio of material and liquid at 1:10, along with ultrasonic wave for 40 minutes. After 12 hours' standing, the mixture was subjected to evaporate and dry. All these processes were preparations of luteolin isolation. Then, the treated powder of peanut shells was extracted with $65 \%$ ethanol and solid to liquid ratio of 1:20 for 3 hours at $80^{\circ} \mathrm{C}$, followed by filtration, evaporation and drying.

HSCCC was used to isolate and prepare natural dyestuff of luteolin and the characteristic absorption wavelength of luteolin was determined through measuring absorbance at $280 \mathrm{~nm}$ by UV/Visible spectrophotometer. The operating conditions were as follows: solvent system of chloroform-methanol-water (4/3/2, $\mathrm{V} / \mathrm{V}$ ), processing speed of $800 \mathrm{rmp} / \mathrm{min}$, pressure of $2.0 \mathrm{Mkpa}$, and flow rate of $0.5 \mathrm{~mL} / \mathrm{min}$.

\subsection{Identification of Luteolin Structure}

The FTIR analysis is an important tool to identify the characteristic functional groups that might be responsible for properties. The structure of luteolin sample was identified by FTIR techniques and the FTIR spectrum was recorded within the range of $4000-400 \mathrm{~cm}^{-1}$. Pressed pellets were prepared by grinding luteolin sample with IR grade $\mathrm{KBr}$ in an agate mortar and pestle and pressed into transparent sheets in press mould under $14 \mathrm{MPa}$ pressure and vacuum condition for 2 - 3 min. We analyzed the result by comparing the FTIR spectrum (Figure 2) of

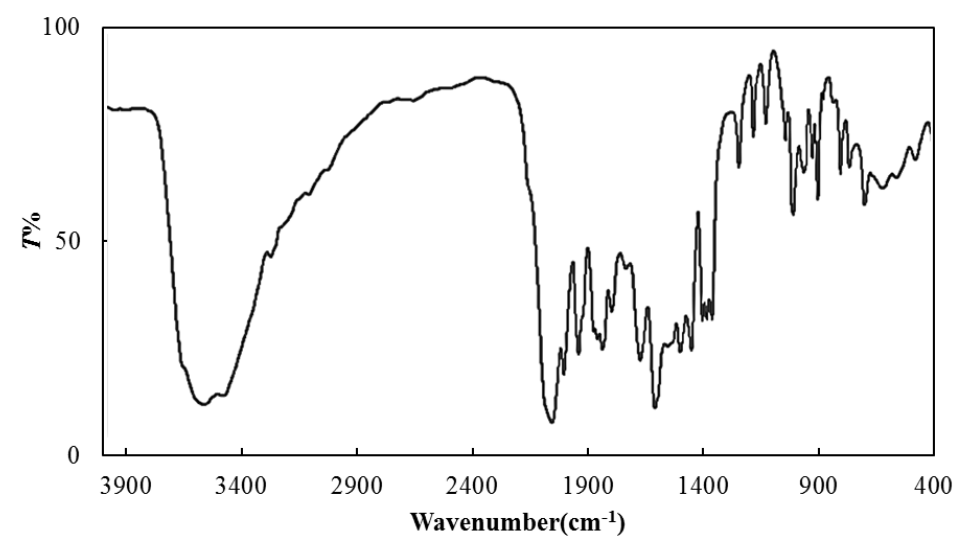

Figure 2. IR spectrum of standard luteolin (98\%). 
luteolin standard sample (98\%) with the isolated luteolin sample's.

\subsection{Dyeing Thermodynamics Experiments}

First, the wool was dried in drying oven. Then, we weighed 15 samples of dried wool and each sample was $0.5000 \mathrm{~g}$. Subsequently, these wool samples were carried out in dyebaths that the bath ratio was 1:50 and the $\mathrm{pH}$ was 4.5 severally at $70^{\circ} \mathrm{C}, 80^{\circ} \mathrm{C}$ and $90^{\circ} \mathrm{C}$ for $90 \mathrm{~min}$. Each dyeing was done for different dye shades of $1,1.25,1.5,1.75,2.0,2.5,3.0$ and 3.5 percent owf. The dyed samples were respectively rinsed with $75 \mathrm{~mL}$ water in order to remove non-absorbed dyes and rinse water was mixed with homologous dyeing residue. We respectively measured the absorbance of each mixed dyeing residue and drew the adsorption isotherms, and dyeing affinity, dyeing enthalpy and dyeing entropy were also calculated using statistical functions [6] [7].

\subsection{Supramolecular Structure Simulation Experiments}

The conjecture was that there was obvious hydrogen bonding interaction between luteolin molecule and wool fiber because of abundant hydroxyl groups in wool fiber molecule and luteolin molecule [8]. The research chose glycine holding a large proportion of amino acid in wool as research object to analyze and discuss the significance of combination manners and space structures when luteolin was used for dyeing wool fabric. The molecular space structures of luteolin and glycine were drawn by molecular simulation software (Gauss View 5.0). The structure was optimized and the frequency was calculated by Gaussian $09 \mathrm{w}$ based on the density functional theories (DFT) of quantum chemistry, by using B3LYP with the $6-31 \mathrm{G}(\mathrm{d})$ basis set at $80^{\circ} \mathrm{C}$ under 1atm pressure [9]. Multiwfn software was applied to analyze the calculation results.

\section{Results and Discussion}

\subsection{Isolation of Luteolin}

The isolation effect of HSCCC is shown in Figure 3. Results show that: flow rate $0.5 \mathrm{~mL} / \mathrm{min}$, pressure $2.0 \mathrm{Mkpa}$, chromatographic column speed $800 \mathrm{rmp} / \mathrm{min}$, peak time was 30 - $60 \mathrm{~min}$, at this time was the best isolation effect and the peak pattern was in good symmetry without wave. As a matter of fact, we collected pure luteolin sample at 38 min of peak time.

\subsection{Identification of Luteolin Structure}

The FTIR spectrum of luteolin sample is shown in Figure 4 and compared with Figure 2. There are some of the same characteristics peaks in these two IR spectra, such as $3407 \mathrm{~cm}^{-1}, 1656 \mathrm{~cm}^{-1}, 1610 \mathrm{~cm}^{-1}, 1505 \mathrm{~cm}^{-1}, 1134 \mathrm{~cm}^{-1}, 1025 \mathrm{~cm}^{-1}$ and $820 \mathrm{~cm}^{-1}$. The truths are $3407 \mathrm{~cm}^{-1}$ is absorption peak of hydroxyl in benzene, $1656 \mathrm{~cm}^{-1}$ is absorption peak of carbonyl, $1610 \mathrm{~cm}^{-1}$ and $1505 \mathrm{~cm}^{-1}$ are skeleton vibration absorption peaks of benzene, and $1134 \mathrm{~cm}^{-1}$ and $1025 \mathrm{~cm}^{-1}$ are stretch vibration absorption peaks of cyclic ether. The characteristics peaks revealed isolated luteolin sample by HSCCC was purified. 


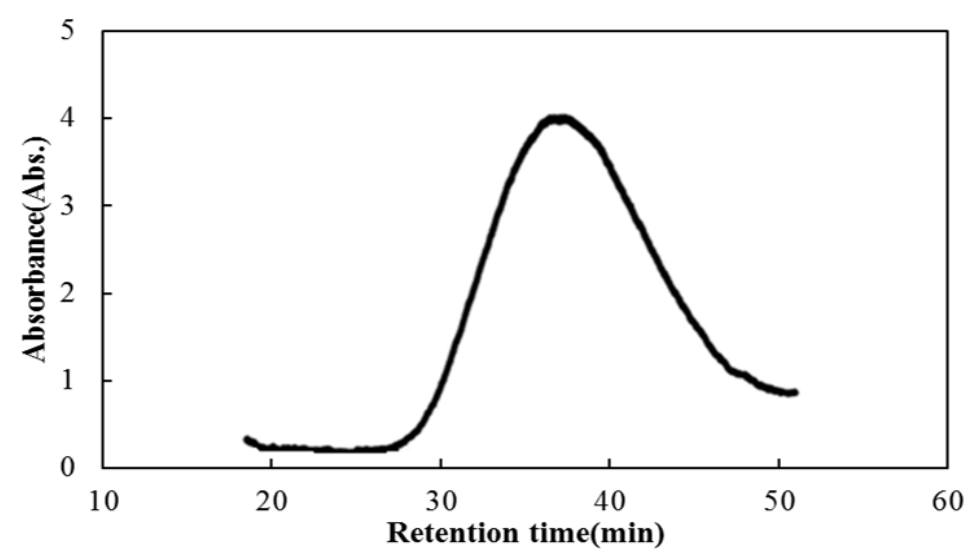

Figure 3. The HSCCC of luteolin.

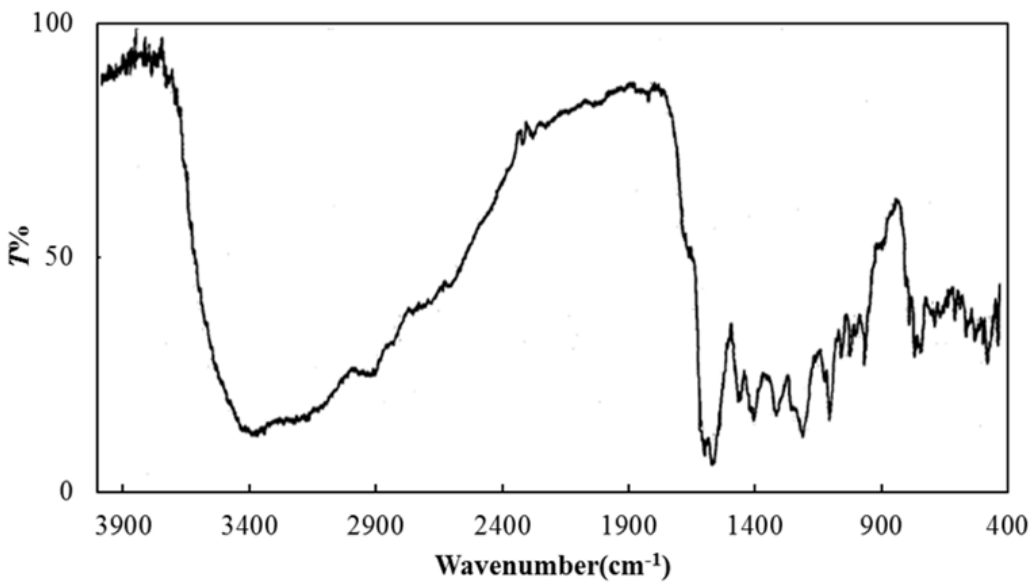

Figure 4. IR spectrum of extracted luteolin (60\%).

\subsection{Dyeing Thermodynamics Research of Lueolin on Wool Fabric}

\subsubsection{Adsorption Isotherms}

The adsorption isotherms of luteolin on wool fiber are described by Nernst isotherms [10] depicted in Figure 5 because the dye concentration on the fiber and in the bath holds are linear relationship. The correlation coefficients $\mathrm{R}^{2}$ are in the range of 0.909 to 0.976 obtained by linear fitting.

The fixation and the adsorption of the dye molecules at the surface or the interior of the fiber are governed by affinity between natural dyestuff of luteolin and wool fiber. Concentration of dye on the fiber is proportional to concentration of dye in the dye liquor when the dye reaches equilibrium. So the inference natural dyestuff of luteolin dyes wool fiber probably mainly by hydrogen bonds.

\subsubsection{Calculation of Standard Affinity, Dyeing Enthalpy and Dyeing Entropy}

The adsorption property of luteolin on wool fiber is similar to the adsorption of disperse dyes on polyester fiber and the nature of luteolin adsorption pertains to distribution mechanism [11]. The thermodynamic parameters such as standard affinity $\left(-\Delta \mu^{0}\right)$, dyeing enthalpy $(\Delta H)$ and dyeing entropy $(\Delta S)$ were computed as shown in Equations (1), (2) and (3) [7] [12]. 


$$
\begin{aligned}
& -\Delta \mu^{0}=R \operatorname{TIn}\left[D_{f}\right] /\left[D_{s}\right] \\
& \Delta H=\left(T_{2} \Delta \mu_{1}-T_{1} \Delta \mu_{2}\right) /\left(T_{2}-T_{1}\right) \\
& -\Delta \mu^{0}=T \Delta S-\Delta H
\end{aligned}
$$

where, $D_{f}$ and $D_{s}$ are the concentration of dye on the fiber and in the dyebath respectively, $\mathrm{T}$ is the temperature and $R$ is a constant standing for 8.314 $\mathrm{J} \cdot(\mathrm{mol} \cdot \mathrm{K})^{-1}$. The thermodynamic parameters and distribution coefficient $\mathrm{K}$ obtained at different temperatures are presented in Table 1.

Table 1 shows distribution coefficients and affinities increased in the wake of the increase of temperature and the values of dyeing enthalpy and dyeing entropy are positive.

The affinity indicates the trend of the sorption behavior of dyes onto fibers and the higher value reflects more energetically favorable sorption [7] [13]. The $\Delta S$ indicates the degree of randomness of dye molecule and the position value of $\Delta S$ manifests higher temperature is more conducive to increase the dyeing affinity and easier to dye fabric during dyeing process [7] [14].

\subsection{Supramolecular Structure of Luteolin on Wool Fabric}

The molecular structures of luteolin and glycine were simulated by Gauss View 5.0 and optimized by Guassian09, as shown in Figure 6.

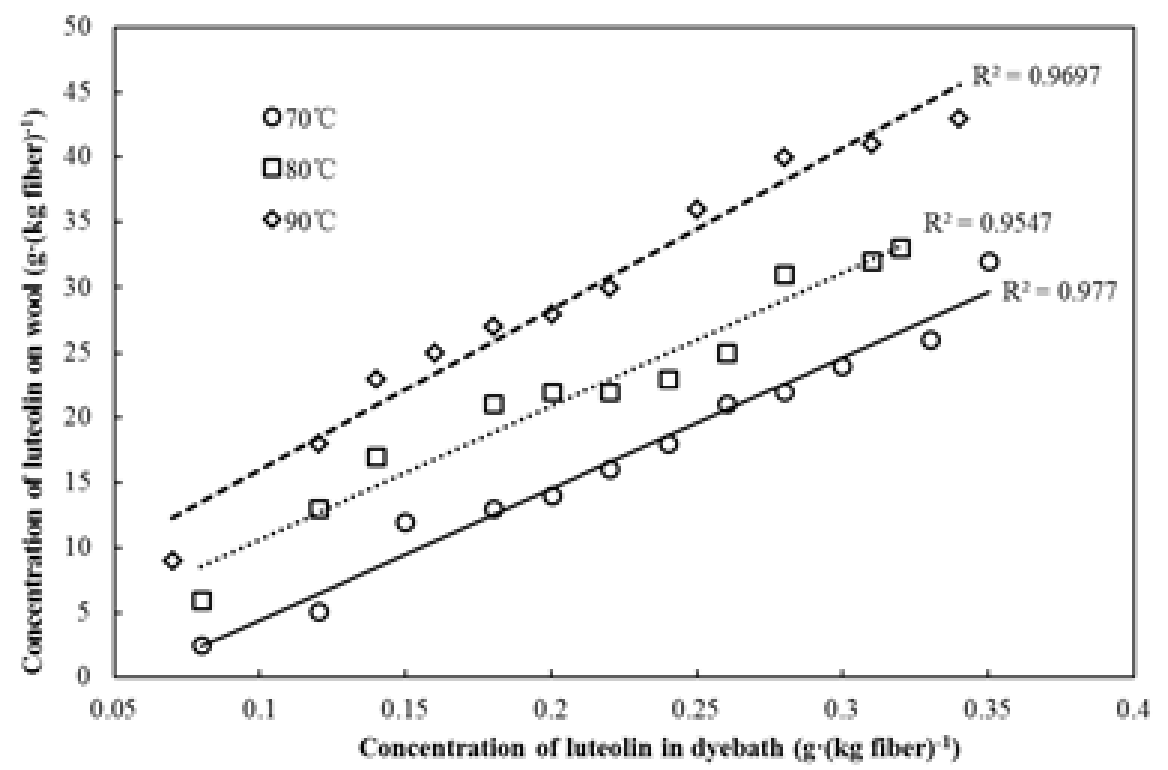

Figure 5. Adsorption isotherms of luteolin on wool fiber.

Table 1. Thermodynamic parameters for luteolin on wool fiber.

\begin{tabular}{ccccc}
\hline Temperature $/{ }^{\circ} \mathrm{C}$ & $\begin{array}{c}\text { Distribution } \\
\text { coefficient } \\
K /\left(\mathrm{L} \cdot \mathrm{kg}^{-1}\right)\end{array}$ & $\begin{array}{c}\text { Standard } \\
\text { affinity } \\
-\Delta \mu /\left(\mathrm{kJ} \cdot \mathrm{mol}^{-1}\right)\end{array}$ & $\begin{array}{c}\text { Dyeing } \\
\text { enthalpy } \\
\Delta H /\left(\mathrm{kJ} \cdot \mathrm{mol}^{-1}\right)\end{array}$ & $\begin{array}{c}\text { Dyeing } \\
\text { entropy } \\
\Delta S / \mathrm{kJ}\left(\mathrm{mol} \cdot \mathrm{K}^{-1}\right)\end{array}$ \\
\hline 70 & 105.13 & 13.28 & 13.78 & 0.079 \\
80 & 120.84 & 14.08 & 13.78 & 0.079 \\
90 & 137.15 & 14.86 & 13.78 & 0.079 \\
\hline
\end{tabular}


The simulation of hydrogen bonds in supramolecular structure elucidates luteolin dyes wool fiber by combining the amino acid with two or three hydrogen bonds. The forms of hydrogen bond in these compounds are $\mathrm{N}-\mathrm{H} \ldots \mathrm{O}$, $\mathrm{C}-\mathrm{H} \cdots \mathrm{O}, \mathrm{C}-\mathrm{O} \cdots \mathrm{H}, \mathrm{O}-\mathrm{H} \cdots \mathrm{N}$ and $\mathrm{O}-\mathrm{H} \cdots \mathrm{O}$. Figure $7(\mathrm{~A} \sim \mathrm{H})$ shows 8 stable compounds without imaginary frequency obtained by structure optimization and frequency calculation of complex space configuration of luteolin and glycine at B3LYP/6-31G(d) level.
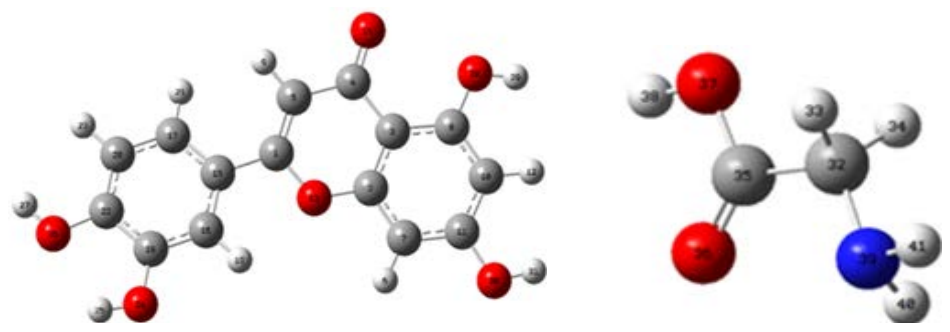

Figure 6. The optimization of molecular structure of luteolin (1) and glycine (2).
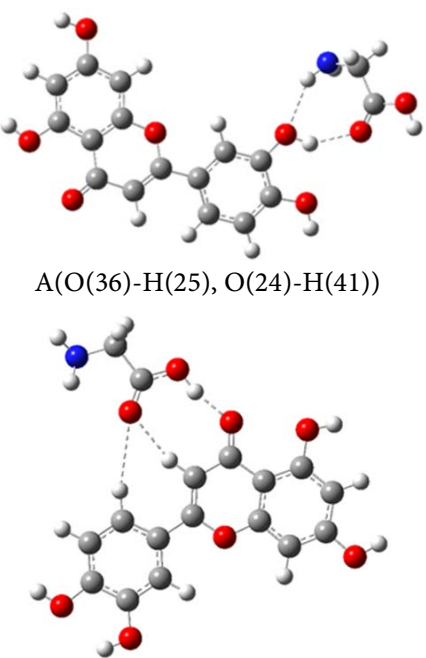

$\mathrm{C}(\mathrm{O}(14)-\mathrm{H}(38), \mathrm{O}(36)-\mathrm{H}(9), \mathrm{O}(36)-\mathrm{H}(21))$

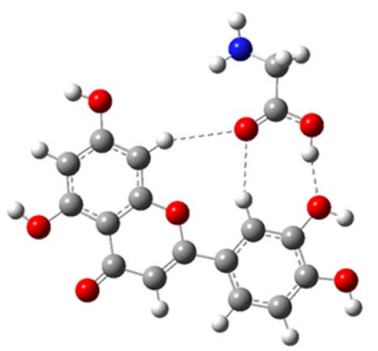

$\mathrm{E}(\mathrm{O}(36)-\mathrm{H}(6), \mathrm{O}(36)-\mathrm{H}(19), \mathrm{O}(24)-\mathrm{H}(38))$

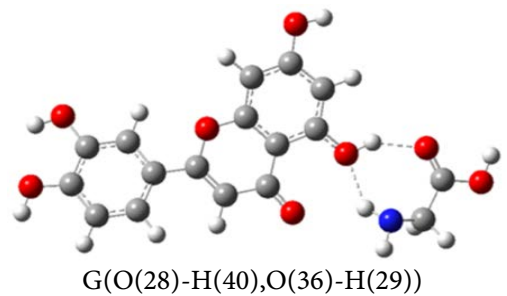

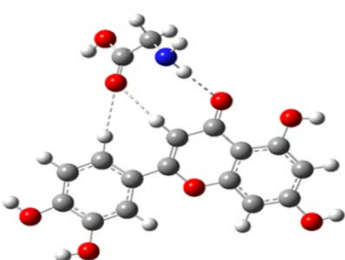

$\mathrm{B}(\mathrm{O}(36)-\mathrm{H}(6), \mathrm{O}(36)-\mathrm{H}(19), \mathrm{O}(24)-\mathrm{H}(40))$

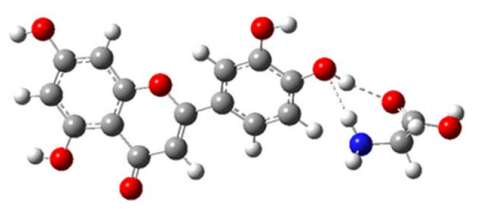

$\mathrm{D}(\mathrm{O}(26)-\mathrm{H}(41), \mathrm{O}(36)-\mathrm{H}(27))$

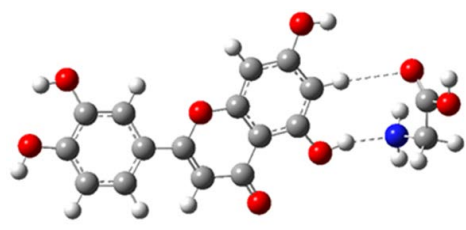

$\mathrm{F}(\mathrm{N}(39)-\mathrm{H}(29), \mathrm{O}(36)-\mathrm{H}(12)$

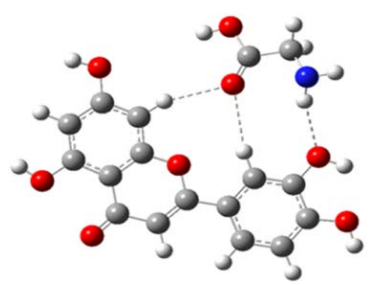

$\mathrm{H}(\mathrm{O}(36)-\mathrm{H}(9), \mathrm{O}(36)-\mathrm{H}(21), \mathrm{O}(14)-\mathrm{H}(40))$

Figure 7. The complex space configurations of luteolin and glycine. 
The Laplacian values elucidate the properties of the bonds between luteolin and glycine [15]. The negative values of $\nabla^{2} \rho c$ illuminate electronic charges are locally concentrated in the critical point region of bonds to form covalent bonds, whereas the positive values of $\nabla^{2} \rho c$ illuminate electronic charges are locally concentrated in every nucleus region to make non covalent bond. The Laplacian values of above 8 stable complexes calculated by Multiwfn were all greater than zero and shown in Table 2. Speculation that the natural dyestuff of luteolin dyes wool fiber by hydrogen-bond interactions is coincident with the results of dyeing thermodynamics research.

Table 3 shows the analyses of the complex of luteolin and glycine from the view of energy. The interaction energy of 8 complexes range from $-61.85 \sim$ $-11.71 \mathrm{~kJ} / \mathrm{mol}$ calibrated by BSSE [16] and the complexes containing three hydrogen bonds are generally more stable than those with two hydrogen bonds because the interaction energy of the former is lower than the latter. This phenomenon demonstrates hydrogen bond possesses additivity and the stability of complex of luteolin and glycine is closely associated with the number of hydrogen bonds. Findings $\mathrm{O}-\mathrm{H}$... $\mathrm{O}$ type of hydrogen bond is more steady than $\mathrm{O}-\mathrm{H} \cdots \mathrm{N}$ type found by the comparisons of $\mathrm{C}$ and $\mathrm{H}$ together with $\mathrm{E}$ and $\mathrm{B}$. Therefore, oxygen atom has a higher electronegativity than nitrogen atom and the hydrogen atoms in oxygen atom expose more thoroughly in order to accept duplet more easily. In this situation, supramolecular structure is the most stable and has lowest energy.

Table 2. The Laplacian calculated at the hydrogen bond critical point.

\begin{tabular}{|c|c|c|}
\hline Complex & Bond position & Laplacian value \\
\hline \multirow{2}{*}{ A } & $\mathrm{O}(36)-\mathrm{H}(25)$ & 0.079 \\
\hline & $\mathrm{O}(24)-\mathrm{H}(41)$ & 0.063 \\
\hline \multirow{3}{*}{ B } & $\mathrm{O}(36)-\mathrm{H}(6)$ & 0.113 \\
\hline & $\mathrm{O}(36)-\mathrm{H}(19)$ & 0.103 \\
\hline & $\mathrm{O}(24)-\mathrm{H}(40)$ & 0.066 \\
\hline \multirow{3}{*}{$\mathrm{C}$} & $\mathrm{O}(14)-\mathrm{H}(38)$ & 0.075 \\
\hline & $\mathrm{O}(36)-\mathrm{H}(9)$ & 0.134 \\
\hline & $\mathrm{O}(36)-\mathrm{H}(21)$ & 0.142 \\
\hline \multirow{2}{*}{$\mathrm{D}$} & $\mathrm{O}(26)-\mathrm{H}(41)$ & 0.063 \\
\hline & $\mathrm{O}(36)-\mathrm{H}(27)$ & 0.081 \\
\hline \multirow{3}{*}{$\mathrm{E}$} & $\mathrm{O}(36)-\mathrm{H}(6)$ & 0.123 \\
\hline & $\mathrm{O}(36)-\mathrm{H}(19)$ & 0.112 \\
\hline & $\mathrm{O}(24)-\mathrm{H}(38)$ & 0.067 \\
\hline \multirow{2}{*}{$\mathrm{F}$} & $\mathrm{N}(39)-\mathrm{H}(29)$ & 0.045 \\
\hline & $\mathrm{O}(36)-\mathrm{H}(12)$ & 0.062 \\
\hline \multirow{2}{*}{ G } & $\mathrm{O}(28)-\mathrm{H}(40)$ & 0.062 \\
\hline & $\mathrm{O}(36)-\mathrm{H}(29)$ & 0.083 \\
\hline \multirow{3}{*}{$\mathrm{H}$} & $\mathrm{O}(36)-\mathrm{H}(9)$ & 0.126 \\
\hline & $\mathrm{O}(36)-\mathrm{H}(21)$ & 0.131 \\
\hline & $\mathrm{O}(14)-\mathrm{H}(40)$ & 0.064 \\
\hline
\end{tabular}


Table 3. Interaction energies and BSSE correction for the complexes on B3LYP/6-31+G* level.

\begin{tabular}{cccc}
\hline Complex & E & BSSE & $\Delta E(\mathrm{~kJ} / \mathrm{mol})$ \\
\hline C & -1313.438416 & 0.001824888 & -61.8524348 \\
H & -1313.433305 & 0.001832724 & -49.81676998 \\
E & -1313.434997 & 0.002306085 & -46.51155166 \\
B & -1313.430066 & 0.00170597 & -36.97144034 \\
G & -1313.426742 & 0.001423471 & -30.55239477 \\
D & -1313.427643 & 0.001893676 & -27.44662518 \\
A & -1313.427222 & 0.00128618 & -20.81140907 \\
F & -1313.421234 & 0.00136405 & -11.71168075 \\
\hline
\end{tabular}

\section{Conclusions}

The optimized extraction condition of luteolin was as follows: $65 \%$ ethanol, ratio of material to liquid 1:20, extraction temperature $80^{\circ} \mathrm{C}, 3 \mathrm{~h}$ and purified luteolin can be obtained in following parameters: chloroform-methanol-water (4/3/2, $\mathrm{V} / \mathrm{V}), 800 \mathrm{rmp} / \mathrm{min}, 2.0 \mathrm{Mkpa}, 0.5 \mathrm{~mL} / \mathrm{min}$ and $280 \mathrm{~nm}$.

The mechanism that luteolin dyed wool fiber mainly by hydrogen bonding were similar to disperse dyes. The thermodynamics study revealed Nernst isotherm fitted well to the adsorption equilibrium data.

The supramolecular simulation demonstrated the complex with hydrogen bonding formed between luteolin and amino acid in wool fiber and the complex containing three hydrogen bonds was in the best stabilization.

The investigation proved the interaction of luteolin on wool fabric depended mainly on weak hydrogen bonds, which were accountable for low color fastness and poor stability.

\section{Acknowledgements}

Financial support from General Program of National Natural Science Foundation of China (Grant No. 51003047), Natural Science Foundation of Jiangsu Province (Grant No. SBK201121603), Higher Education Institutions Natural Science Foundation of Jiangsu Educational Commission (Grant No. 09KJB540001) and Open Foundation of Hubei Key Laboratory of biomass fiber and Ecological Dyeing and Finishing (Grant No. 201603) are gratefully acknowledged.

\section{References}

[1] Gong, H., Zhou, H., Forrest, R.H., Li, S., Wang, J., Dyer, J.M., Luo, Y. and Hickford, J.G.H. (2016) Wool Keratin-Associated Protein Genes in Sheep-A Review. Genes, 7, 24. https://doi.org/10.3390/genes7060024

[2] Nabavi, S.F., Braidy, N., Gortzi, O., Sobarzo-Sanchez, E., Daglia, M., SkalickaWoźniak, K. and Nabavi, S.M. (2015) Luteolin as an Anti-Inflammatory and Neuroprotective Agent: A Brief Review. Brain Research Bulletin, 119, 1-11. https://doi.org/10.1016/j.brainresbull.2015.09.002 
[3] Dranik, L.I. and Dolganenko, L.G. (1973) Flavonoids of the Fruit of Daucus Carota. Chemistry of Natural Compounds, 9, 635-635. https://doi.org/10.1007/BF00564395

[4] Bravo, L. (1998) Polyphenols: Chemistry, Dietary Sources, Metabolism, and Nutritional Significance. Nutrition Reviews, 56, 317-333. https://doi.org/10.1111/j.1753-4887.1998.tb01670.x

[5] Lin, Y., Shi, R., Wang, X. and Shen, H.M. (2008) Luteolin, a Flavonoid with Potential for Cancer Prevention and Therapy. Current Cancer Drug Targets, 8, 634-646. https://doi.org/10.2174/156800908786241050

[6] Wu, C.H. (2007) Adsorption of Reactive Dye onto Carbon Nanotubes: Equilibrium, Kinetics and Thermodynamics. Journal of Hazardous Materials, 144, 93-100. https://doi.org/10.1016/j.jhazmat.2006.09.083

[7] Tahir, M.A., Bhatti, H.N. and Iqbal, M. (2016) Solar Red and Brittle Blue Direct Dyes Adsorption onto Eucalyptus Angophoroides Bark: Equilibrium, Kinetics and Thermodynamic Studies. Journal of Environmental Chemical Engineering, 4, 2431 2439. https://doi.org/10.1016/j.jece.2016.04.020

[8] Li, M., Song, K., Xie, K. and Hou, A. (2014) Crystal Morphology, Dispersing Stability and Dyeing Property of the Disperse Dye Based on Benzisothiazole. Pigment \& Resin Technology, 43, 365-370. https://doi.org/10.1108/PRT-10-2013-0099

[9] Yang, Y., Weaver, M.N. and Jr, M.K. (2009) Assessment of the " $6-31+G^{* *}+$ LANL2DZ" Mixed Basis Set Coupled with Density Functional Theory Methods and the Effective Core Potential: Prediction of Heats of Formation and Ionization Potentials for First-Row-Transition-Metal Complexes. Journal of Physical Chemistry A, 113, 9843-9851. https://doi.org/10.1021/jp807643p

[10] Knyazkov, D.A., Slavinskaya, N.A., Dmitriev, A. and Riedel, U. (2016) Structure of an n-Heptane/Toluene Flame: Molecular Beam Mass Spectrometry and Computer Simulation Investigations. Combustion Explosion and Shock Waves, 52, 142-154. https://doi.org/10.1134/S0010508216020039

[11] Qian, H.F. and Song, X.Y. (2007) The Structure of Azo Disperse Dyes and Its Distribution on Polyurethane Fiber Blend with Polyester, or Polyamide Fiber. Dyes \& Pigments, 74, 672-676. https://doi.org/10.1016/j.dyepig.2006.04.011

[12] Khan, I., Min, T.K., Azizi, A.K. and Man, Z. (2015) Effective Removal of Methylene Blue from Water Using Phosphoric Acid Based Geopolymers: Synthesis, Characterizations and Adsorption Studies. RSC Advances, 5, 61410-61420. https://doi.org/10.1039/C5RA08255B

[13] Ncibi, M.C., Mahjoub, B. and Seffen, M. (2007) Kinetic and Equilibrium Studies of Methylene Blue Biosorption by Posidonia Oceanica (L.) Fibres. Journal of Hazardous Materials, 139, 280-285. https://doi.org/10.1016/j.jhazmat.2006.06.029

[14] Yadav, S., Srivastava, V., Banerjee, S., Weng, C.H. and Sharma, Y.C. (2013) Adsorption Characteristics of Modified Sand for the Removal of Hexavalent Chromium Ions from Aqueous Solutions: Kinetic, Thermodynamic and Equilibrium Studies. Catena, 100, 120-127. https://doi.org/10.1016/j.catena.2012.08.002

[15] Bader, R.F.W. and Legare, D.A. (1992) Properties of Atoms in Molecules: Structures and Reactivities of Boranes and Carboranes. Canadian Journal of Chemistry, 70, 657-676. https://doi.org/10.1139/v92-089

[16] Asturiol, D., Duran, M. and Salvador, P. (2009) Intramolecular Basis Set Superposition Error Effects on the Planarity of DNA and RNA Nucleobases. Journal of Chemical Theory \& Computation, 5, 2574-2581. https://doi.org/10.1021/ct900056u 
Submit or recommend next manuscript to SCIRP and we will provide best service for you:

Accepting pre-submission inquiries through Email, Facebook, LinkedIn, Twitter, etc. A wide selection of journals (inclusive of 9 subjects, more than 200 journals)

Providing 24-hour high-quality service

User-friendly online submission system

Fair and swift peer-review system

Efficient typesetting and proofreading procedure

Display of the result of downloads and visits, as well as the number of cited articles Maximum dissemination of your research work

Submit your manuscript at: http://papersubmission.scirp.org/

Or contact wjet@scirp.org 